\title{
Glove Accumulation of Pesticide Residues for Strawberry Harvester Exposure Assessment
}

\author{
Yanhong $\mathrm{Li} \cdot \mathrm{Li}$ Chen $\cdot$ Zhenshan Chen $\cdot$ \\ Joe Coehlo $\cdot$ Li Cui · Yu Liu • Terry Lopez • \\ Gayatri Sankaran $\cdot$ Helen Vega $\cdot$ Robert Krieger
}

Received: 24 January 2011/ Accepted: 30 March 2011/Published online: 19 April 2011

(C) Springer Science+Business Media, LLC 2011

\begin{abstract}
We investigated the accumulation of pesticide residues on rubber latex gloves that are used by strawberry harvesters to protect their skin, reduce pesticide exposure and promote food safety. Gloves accumulated residues of 16 active ingredients including azoxystrobin, bifenthrin, boscalid, captan, cyprodinil, fenhexamid, fenpropathrin, fludioxonil, hexythiazox, malathion, methomyl, naled, propiconazole, pyraclostrobin, quinoline, and quinoxyfen at different times. Glove residue accumulation $\left(\mathrm{t}_{1 / 2} 2.8-3.7\right.$ d) was very similar to the dissipation of DFRs $\left(\mathrm{t}_{1} / 22.1-3.0\right.$ d) during the first 3 weeks after malathion applications. Dermal malathion dose was $0.2 \mathrm{mg} / \mathrm{kg}$ at the preharvest interval and declined to trace levels during the following 3 months. Glove accumulation of malathion indicated trace surface residue availability and was used to assess the relationship between dislodgable foliar residues and potential hand exposure.
\end{abstract}

Keywords Pesticide exposure - Dermal exposure · Latex gloves $\cdot$ Dosimetry $\cdot$ Malathion

Harvester pesticide exposures occur primarily due to hand contact with sprayed leaf surfaces (Iwata et al. 1977; Krieger et al. 1991; Krieger et al. 2006). Historically, Durham and Wolfe (1962) were amongst the first to have

Y. Li · L. Chen · Z. Chen - L. Cui · Y. Liu - T. Lopez ·

G. Sankaran · H. Vega $\cdot$ R. Krieger $(\bowtie)$

Department of Entomology, University of California,

Riverside, CA 02521, USA

e-mail: bob.krieger@ucr.edu

J. Coehlo

DB Specialty Farms, 313 E. Plaza Drive \#12,

Santa Maria, CA 93456, USA studied pesticide exposures using direct and indirect measurements. The "direct" method entailed trapping the chemical as it contacted workmen during the work day. Direct methods included measuring pesticides retained on external clothing, gauze pads, or gloves. "Indirect" methods, which provided indirect indication of potential for skin exposure, included plant surface-sampling techniques and biological monitoring (van Hemmen et al. 2006). Direct methods were considered easier to perform than indirect methods, but total potential exposure estimates were difficult to relate to absorbed dose.

Some strawberry harvesters use light latex gloves to reduce pesticide exposure, cosmetically protect the skin from accumulation of dirt and juice, and reduce the likelihood of food borne illness in consumers (Unpublished observations). Hand exposures are very important during strawberry harvesting (Bradman et al. 2008; Krieger et al. 1991; Zhang 2005). Cotton glove residues represented $60-95 \%$ of the total external pesticide exposure in unpublished EPA-sponsored studies done in the early 1980s (Li 2009). However, cotton gloves being a 3 dimensional woven matrix may overestimate hand exposure by several-fold (Ross et al. 2000). Wearing rubber gloves reduced harvester captan exposure about 50\% compared to bare-handed harvesters based upon urine biomonitoring (Krieger and Dinoff 2000).

Pilot studies reported here have shown that rubber latex gloves accumulate pesticide residue. If hands were the most important route of harvester exposure, a glove dosimeter with properties less like absorbent cotton may become a direct indicator of potential dermal exposure. Here we report preliminary studies of glove accumulation of pesticide residues to measure residue availability and potential harvester hand exposure from samples collected over a 5-year interval. 


\section{Materials and Methods}

Strawberry harvesters at DB Specialty Farms in Santa Maria, CA. are routinely provided professional grade, powder-free rubber latex gloves as required personal protective equipment. Glove samples were those discarded at each break. Harvesters wore new gloves during each succeeding 2-2.5 h work period. Most collections of gloves for analysis were made at mid-day, but gloves were also available mid-morning, mid-afternoon and at the endof-shift. Collections consisted of 10 or 12 pairs stored individually in quart-sized polyethylene Ziploc bags that were stored frozen $\left(-20^{\circ} \mathrm{C}\right)$ until shipment to the University of California at Riverside Personal Chemical Exposure Program (UCR PCEP) for frozen storage prior to analysis.

Gloves were cut with ethyl acetate rinsed scissors (about 2-4 $\mathrm{cm}^{2}$ pieces) before being double-bagged (Ziploc) and vigorously extracted in the bags (Eberbach shaker at high frequency for $20 \mathrm{~min}$ ) with $150 \mathrm{~mL}$ ethyl acetate. The volume was reduced to $\sim 2-20 \mathrm{~mL}$ using a rotary evaporator. The samples were then labeled, packaged and either shipped to primuslabs.com for multiresidue analysis PAM 242.1 (Pesticide Analytical Manual) or analyzed at UCR PCEP for malathion or fenpropathrin.

The influence of moisture on malathion accumulation was studied in sets of gloves of 12 harvesters collected after the mid-morning and mid-day lunch breaks (morning) and after the mid-afternoon and end-of-shift (afternoon) work periods. Collections were made 3, 6, and 9 days following application of malathion at $2 \mathrm{lb} / \mathrm{A}$. The dislodgeable foliar residues (DFR whole leaves, $\mu \mathrm{g} / \mathrm{cm}^{2}$ ) in triplicate were also measured (Iwata et al. 1977). This work was done in 2004 in accord with an approved UCR, Human Subjects Review Board protocol.

Multiresidue analysis during the spring of 2008 utilized mid-day collections of gloves (following 2-2.5 h harvesting) that were extracted and analyzed by primuslabs.com (Luke et al. 1981). Sixteen pesticides were included in the survey (Table 1). Each was applied at the label rate as indicated by the pest control adviser. All active ingredients were detected (2-7 pesticides were found in any given pair) in multiple glove extracts, but extraction efficiencies were not determined for most of the analytes (Table 1). The recoveries of captan, fenpropathrin, and malathion in the survey ranged from $88 \%$ to $111 \%, 67 \%$ to $106 \%$, and from $95 \%$ to $161 \%$, respectively. Concurrent monitoring of malathion and fenpropathrin accumulation on gloves in 2005 followed application of a tank mix containing the two insecticides at the same application rate $(1 \mathrm{lb} / \mathrm{A})$.

A more extensive recovery study of malathion and fenpropathrin was conducted to demonstrate the characteristics of the extraction and analysis scheme that features collection and extraction in a single polyethylene Ziploc
Table 1 Pesticides accumulated on latex gloves of strawberry harvesters

\begin{tabular}{ll}
\hline Pesticide & Active Ingredient \\
\hline Abound & Azoxystrobin \\
Brigade & Bifenthrin \\
Captan & Captan \\
Danitol & Fenpropathrin \\
Dibrom & Naled \\
Elevate & Fenhexamid \\
Lannate & Methomyl \\
Malathion & Malathion \\
Orbit & Propiconazole \\
Pristine & Pyraclostrobin/boscalid \\
Quintec & Quinoxyfen/quinoline \\
Savey & Hexythiazox \\
Switch & Cyprodinil/fludioxonil \\
\hline
\end{tabular}

bag (Table 2). In this case 2 additional procedures to characterize the method were performed. One $\mathrm{mL}$ solutions of $5 \mu \mathrm{g}, 50 \mu \mathrm{g}$, and $250 \mu \mathrm{g}$ of malathion and fenpropathrin were added directly to Ziploc bags, the solvent was air dried for $2-3 \mathrm{~h}$, and the bags stored at $-20^{\circ} \mathrm{C}$ before extraction as above after $24 \mathrm{~h}$. Additionally, we measured the residual analyte remaining after extraction of spiked bags/gloves and transfer of the solvent to the rotary evaporator for volume reduction. Residual solvent $(13 \mathrm{~mL})$ was determined gravimetrically and recoveries adjusted by the resulting $150 \mathrm{~mL}$ (nominal)/137 $\mathrm{mL}$ (measured) correction factor in Table 2.

Long-term monitoring of malathion surface residues was done using gloves randomly collected at the mid-day break from harvesters at DB Specialty Farms in Santa Maria, CA in 2005, 2006, and 2007. The malathion application rates were 1,2 , and $2 \mathrm{lbs} / \mathrm{A}$ for the 28,78 , and 94 day respective monitoring periods. Gloves were collected by field supervisors every 3-5 days. Each collection consisted of 10 pairs of gloves (from 20-35 harvesters). Gloves were stored and processed as described above.

Glove extracts were analyzed on a Hewlett-Packard $5890 \mathrm{GC}$ equipped with a $30 \mathrm{~m} \times 0.32 \mathrm{~mm} \times 0.25 \mu \mathrm{m}$ film fused silica column and either flame photometric (FPD) or electron capture (ECD) detectors. Helium was the carrier gas at $2 \mathrm{~mL} / \mathrm{min}$. The temperature program used for malathion analysis was: $50^{\circ} \mathrm{C}$ for $1 \mathrm{~min}$, then ramped up at $20^{\circ} \mathrm{C} / \mathrm{min}$ to $300^{\circ} \mathrm{C}$ where it was held for $3 \mathrm{~min}$. Chromatograms for malathion were recorded from a FPD and integrated by peak area (Table 2). The temperature program used for fenpropathrin analysis was: $100^{\circ} \mathrm{C}$ for $1 \mathrm{~min}$, then ramped up at $20^{\circ} \mathrm{C} / \mathrm{min}$ to $230^{\circ} \mathrm{C}$, and then increased at $5^{\circ} \mathrm{C} / \mathrm{min}$ to $300^{\circ} \mathrm{C}$ and held at this temperature for 1 min. Chromatograms were recorded from an ECD and 
Table 2 Recovery of malathion and fenpropathrin from pair of rubber latex gloves in one-quart polyethylene Ziploc bags

\begin{tabular}{|c|c|c|c|c|c|c|c|}
\hline Pesticide $^{\mathrm{a}}$ & $\begin{array}{l}\text { Linearity range }{ }^{b} \\
(\mu \mathrm{g} / \mathrm{mL})\end{array}$ & $\mathrm{R}^{2}$ & $\begin{array}{l}\mathrm{LOD}^{\mathrm{c}} \\
(\mu \mathrm{g} / \mathrm{mL})\end{array}$ & $\begin{array}{l}\mathrm{LOQ}^{\mathrm{d}} \\
(\mu \mathrm{g} / \mathrm{mL})\end{array}$ & $\begin{array}{l}\text { Fortification level } \\
(\mu \mathrm{g} / \mathrm{mL})\end{array}$ & $\begin{array}{l}\text { Recovery } \pm \mathrm{SD}^{\mathrm{f}} \\
(n=3 ; \%)\end{array}$ & $\operatorname{RSD}^{\mathrm{g}}(\%)$ \\
\hline \multirow[t]{3}{*}{ Malathion } & \multirow[t]{3}{*}{$1-100$} & \multirow[t]{3}{*}{0.9999} & \multirow[t]{3}{*}{0.611} & \multirow[t]{3}{*}{2.04} & 5 & $104.4 \pm 9.6$ & $9 \%$ \\
\hline & & & & & 50 & $141.3 \pm 4.5$ & $3 \%$ \\
\hline & & & & & 250 & $126.1 \pm 12.3$ & $10 \%$ \\
\hline \multirow[t]{3}{*}{ Fenpropathrin } & \multirow[t]{3}{*}{$1-100$} & \multirow[t]{3}{*}{0.9958} & \multirow[t]{3}{*}{0.295} & \multirow[t]{3}{*}{0.983} & 5 & $96.6 \pm 20.5$ & $21 \%$ \\
\hline & & & & & 50 & $100.2 \pm 4.9$ & $5 \%$ \\
\hline & & & & & 250 & $92.9 \pm 2.1$ & $2 \%$ \\
\hline
\end{tabular}

${ }^{\mathrm{a}}$ Pesticide applied to a pair of rubber latex gloves in one-quart polyethylene Ziploc bag. ${ }^{\mathrm{b}}$ Standard curve range on GC-ECD and GC-FPD. ${ }^{c}$ Limit of Detection of the GC-FPD for malathion and GC-ECD for fenpropathrin. ${ }^{\mathrm{d}}$ Limit of Quantification of the GC-FPD for malathion and GC-ECD for fenpropathrin. ${ }^{\mathrm{e}}$ Fortification levels used as liquid spikes. ${ }^{\mathrm{f}}$ Adjusted recovery using $150 \mathrm{~mL}$ (nominal)/137 mL (measured) correction factor. ${ }^{\mathrm{g}}$ Percent Relative Standard Deviation $=[$ standard deviation $\times 100] /$ mean

integrated by peak area (Table 2). Glove accumulation per work period $(2-2.5 \mathrm{~h})$ is expressed as $\mu \mathrm{g}$ malathion or fenpropathrin/pair.

All statistical analyses were performed using the SAS system version 9 for Microsoft Windows. One-Way ANOVA test followed by Tukey multiple comparison using the General Linear Model was conducted to test the changes of glove residues over time. Two Factor Design was used to compare malathion glove residue and fenpropathrin glove residue over time. The significance level is 0.01 .

\section{Results and Discussion}

Measurements of pesticide accumulation on their rubber latex gloves have been performed among harvesters who wore gloves as required personal protective equipment. Latex sensitivity has not been observed among harvesters during the past 7 years during which the gloves have been extensively used. The nature of the work task and the quality of the latex in powderless gloves used by harvesters may minimize the likelihood of persons developing latex sensitivity. This issue warrants continued evaluation. During that period the importance of hands as a route of exposure has been confirmed in pesticide monitoring studies that have used gloves to detect multiple pesticides as surface residues, measure malathion accumulation as an indicator of trace surface residue availability, and assess the relationship between DFR and a potential hand transfer coefficient. Latex gloves warrant evaluation in exposure assessment and risk characterization since they may become useful as non-invasive, direct dosimeters for measurement of available levels of field residues. They have a direct advantage over cotton gloves in that they do not absorb water, preserve tactile perception and are commonly used by many workers.
Random glove collections at the mid-day break during the 2008 season and periodic multiresidue analysis revealed 13 analytes on rubber latex gloves obtained from strawberry harvesters (Table 1). The survey utilized 28 collections that yielded from 2 to 7 analytes in single analyses. The amounts detected were highly variable and generally declined as the time from application increased. Overall, the residues that accumulated on gloves during $2 \mathrm{~h}$ to $2.5 \mathrm{~h}$ work periods (Table 1 ) ranged from $0.5 \mu \mathrm{g} /$ pair to as high as $20 \mathrm{mg} / \mathrm{pair}$. The conditions for analysis of the various analytes were not optimized, therefore, the results have only qualitative significance (Table 1). The relationship between latex glove residues and harvester exposure is unknown and the subject of continuing research.

The results of the recovery study of malathion and fenpropathrin revealed the characteristics of the extraction and analysis scheme that features collection and extraction in a single polyethylene Ziploc bag (Table 2). The performance of the analytical procedures was evaluated to determine whether the polyethylene bags interfered with the measurement of glove residues of malathion and fenpropathrin. Recovery of malathion ranged from $104.4 \%$ to $141.3 \%$ and recovery of fenpropathrin ranged from $92.9 \%$ to $100.2 \%$ using liquid spikes $(5,50$ and $250 \mu \mathrm{g}$ of each analyte) of rubber latex gloves in polyethylene Ziploc bags. Gravimetric analysis showed that $13 \mathrm{~mL}$ ethyl acetate remained in the bags and cut gloves after the solvent was transferred to the rotary evaporator. A second extraction demonstrated that the residual analytes were primarily derived from the residual solvent (9.3-19.3\% malathion and $7.5-12.4 \%$ fenpropathrin) remaining in the bags. Recoveries shown in Table 2 were adjusted by the resulting $150 \mathrm{~mL}$ (nominal)/137 mL (measured) correction factor. An additional set of liquid spikes were added directly to the polyethylene bags to evaluate potential adsorption. In that case the recoveries of malathion ranged from $82.4 \%$ to $90.7 \%$ and recovery of fenpropathrin ranged from $58.5 \%$ 
to $79.8 \%$ (from liquid spikes). We concluded that residual analyte results primarily from residual solvent remaining in the bags at the transfer to the rotary evaporator and that use of polyethylene Ziploc bags for collection, storage, and extraction of glove samples minimized sample handling and facilitated the analysis of malathion and fenpropathrin.

Following application of a tank mix of fenpropathrin and malathion the gloves of harvesters were analyzed for accumulated residues of each insecticide. The highest fenpropathrin and malathion residues occurred at the first harvest $4 \mathrm{~d}$ after application. A similar pattern of glove retention and residue decay was seen for both insecticides. The glove levels declined biphasically. The first order halflife was $3.5 \mathrm{~d}$ for fenpropathrin and $2.7 \mathrm{~d}$ for malathion for the initial $18 \mathrm{~d}$ of the study period. Exposure estimates based upon residues accumulated on gloves must acknowledge that biphasic dissipation of surface residues may result in underestimation of early exposures and overestimation of later exposures if derived from pseudofirst order decay rates (Whitmyre et al. 2003). Gloves accumulated more fenpropathrin than malathion at each collection during the $25 \mathrm{~d}$ study period, but the difference was not significant $(p=0.9334)$. Linear regression analysis indicated a strong correlation relationship between malathion residue and fenpropathrin residue $\left(\mathrm{R}^{2}=0.9377\right.$, $p=0.0001)$.

The overarching goal of our research is estimation of harvester exposure. Non-invasive procedures that rely upon environmental measurements of available residues such as DFRs are particularly useful (van Hemmen et al. 2006; Krieger et al. 1991). When the DFR at the PHI was used to estimate potential whole body external exposure using an empirical transfer coefficient of $3,000 \mathrm{~cm}^{2} / \mathrm{h}$ (Dong 1999), the potential external harvester exposure (without gloves) was calculated as follows:

$0.132 \mu \mathrm{g} / \mathrm{cm}^{2} \times 3,000 \mathrm{~cm}^{2} / \mathrm{h} \times 8 \mathrm{~h}=3168 \mu \mathrm{g} /$ person

Typically DFR declines very rapidly (Table 3 ). The estimated external harvester exposure was $288 \mu \mathrm{g} /$ person just 3 days later when the DFR was $0.012 \mu \mathrm{g} / \mathrm{cm}^{2}$. Gloves accumulate the transferable residue for longer durations and at higher levels than predicted by DFR, but the relationship between glove residue and harvester exposure is unknown. Based upon the data presented in Table 3, harvester hand exposure will be substantially less than the amount accumulated on the latex glove matrix.

The accumulation of malathion on gloves was monitored over extended periods in 2005, 2006, and 2007 (Fig. 1) to assess the availability of foliage residues. Malathion residues on gloves at the 3 day preharvest interval (PHI) were highest ranging from 481 to $1670 \mu \mathrm{g} /$ pair $(n=10)$. The glove residues declined rapidly during the next two to 3 weeks after malathion application followed by long-term decay to very low levels. Malathion glove residues after a month post-application were already less than $10 \mu \mathrm{g} / \mathrm{pair}$ during the $2-2.5 \mathrm{~h}$ work periods. The lowest measurable average residue level was about $1 \mu \mathrm{g} / \mathrm{pair}$.

Malathion accumulated on gloves at the PHI was used to construct a reasonable, worst case estimate of absorbed dosage of a $70 \mathrm{~kg}$ harvester. The highest accumulated residue of $1,670 \mu \mathrm{g} / \mathrm{pair} /$ work period was assumed for 4 work periods to yield $6,680 \mu \mathrm{g} / \mathrm{day}$ of external hand exposure. Based upon urine biomonitoring of gloved and bare-handed strawberry harvesters it was estimated that gloved hands conservatively contribute $50 \%$ of the absorbed dose (Krieger 1995 ) relative to the $65 \%$ to $90 \%$ found in the above mentioned EPA studies. If the external dose is assumed to be $100 \%$ available and if hands represent $50 \%$ of the potential dermal dose, the default dermal dosage is $0.2 \mathrm{mg} / \mathrm{kg}$ [i.e., $(6680 \mu \mathrm{g} \times 100 / 50) / 70 \mathrm{~kg}]$. This potential dosage at the PHI is well below levels of health or regulatory concern for malathion. A dermal Bench Mark Dosage 20 of $127 \mathrm{mg} / \mathrm{kg} /$ day is equivalent to the NOAEL of malathion for red blood cell cholinesterase (Jensen and Whatling 2010). If complete absorption of malathion accumulated on gloves at later time periods (Fig. 1) is assumed, the resulting low dosages quickly become toxicologically insignificant and biologically unmeasurable (Krieger and Dinoff 2000).

Table 3 Dislodgeable foliar residues and harvester exposure measures following malathion application in commercial strawberry production

\begin{tabular}{|c|c|c|c|c|c|}
\hline \multirow[t]{2}{*}{ Day $^{a}$} & \multirow[t]{2}{*}{$\operatorname{DFR}\left(\mu \mathrm{g} / \mathrm{cm}^{2}\right)$} & \multirow{2}{*}{$\begin{array}{l}\text { External exposure } \\
(\mu \mathrm{g} / \text { worker })^{\mathrm{b}}\end{array}$} & \multicolumn{3}{|c|}{ Glove residue ( $\mu \mathrm{g} /$ worker $)^{\mathrm{c}}$} \\
\hline & & & Morning & Afternoon & Total \\
\hline 1 & $0.155 \pm 0.006$ & - & - & - & - \\
\hline 3 & $0.132 \pm 0.059$ & 3168 & $5295 \pm 1123^{\mathrm{a}}$ & $1344 \pm 663^{\mathrm{a}}$ & 6639 \\
\hline 6 & $0.012 \pm 0.002$ & 288 & $1870 \pm 741^{\mathrm{b}}$ & $550 \pm 168^{\mathrm{b}}$ & 2420 \\
\hline 9 & $0.009 \pm 0.004$ & 216 & $935 \pm 662$ & - & - \\
\hline
\end{tabular}

${ }^{\mathrm{a}}$ Malathion applied on day 0 at $2 \mathrm{lb} / \mathrm{A} .{ }^{\mathrm{b}}$ External exposure $=\mathrm{DFR} \times 3000 \mathrm{~cm}^{2} / \mathrm{h} \times 8 \mathrm{~h}$

c Twelve workers supplied gloves at the end of each work period. The mid-morning and mid-day collection and the mid- afternoon and end-ofshift collection of rubber latex gloves were each pooled. Superscripts ${ }^{a}$ and ${ }^{b}$ indicate significant differences between morning and afternoon glove residues $(p<0.05)$ 


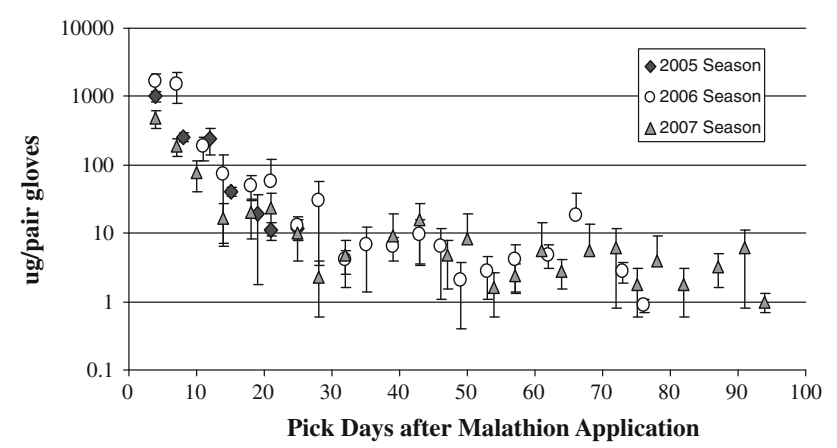

Fig. 1 Rubber latex glove accumulation of malathion residue during strawberry harvesting in 2005, 2006, and 2007. Gloves $(n=10)$ were collected by field operators following malathion application during 3 week to 3 month periods in Santa Maria, CA. The mean and s.d. of glove malathion residues for each collection is represented

Malathion accumulation on latex gloves in 2005, 2006, and 2007 is shown in Fig. 1. In each case the rate of decline in glove residue accumulation was very similar to the dissipation of DFRs during the first 3 weeks after the malathion applications. The half-lives of the first order dissipation curves during the first 3 weeks following application (the alpha phase, Whitmyre et al., 2003) for the glove residues shown in Fig. 1 were 2.8, 3.6 and 3.7 d. In 2006 and 2007 the DFR $\mathrm{t}_{1 / 2} \mathrm{~s}$ were $2.1 \mathrm{~d}$ and $3.0 \mathrm{~d}$, respectively. One-Way ANOVA test demonstrated that glove residues decreased significantly over time in all cases $(p<0.0001)$. However, further Tukey multiple comparison indicated that there was no significant difference in glove residues after 2 weeks (after Days 15, 11, and 14 in 2005, 2006, and 2007, respectively).

The variability seen among studies and also within each collection likely represents the random sampling of persons within large work crews (up to 35 persons) during routine harvesting of treated fields. The actual work periods and characteristic work practices of harvesters who provided samples were unregulated and unknown. Plant growth dilution also contributed to the variability, but it was not assessed during this research.

As shown in Table 3, the daily worker glove accumulation of malathion based upon the amounts retained after each work period more than doubled the estimate of potential external harvester exposure based upon the DFR and the transfer coefficient $\left(3,000 \mathrm{~cm}^{2} / \mathrm{h}\right.$; Dong 1999):

$5295_{\text {morning }}+1344_{\text {afternoon }}=6639 \mu \mathrm{g} /$ person $_{\text {gloves }}$

Morning dew is a regular occurrence in the strawberry fields of the central California coast. Dew may influence glove accumulation of pesticide residues since moisture enhanced the transferability of surface residues (Williams et al. 2005). The morning accumulation of malathion was 3- to 4-times greater than the glove level in the afternoon.
The morning malathion glove levels were significantly greater than the malathion levels accumulated in the afternoon (ANOVA, $p<0.05$ ) as shown in Table 3 .

The accumulation of insecticide by rubber latex gloves in the presence of moisture was substantial and made it difficult to predict actual dermal dose under field conditions due to the day-to-day variability of morning weather conditions. Importantly, followup studies have shown that when moisture is present during the first work period of the day, higher rates of accumulation on glove dosimeters result, but that moisture does not increase the availability of malathion for dermal absorption based upon urine biomonitoring (Zhang 2005). Our subsequent field studies using gloves have avoided sampling during the first work period when variable amounts of morning dew may unduly influence residue accumulation. Moisture will likely effect the performance of other direct dosimeters (Zweig et al. 1985; Zhang 2005).

The availability of foliage residues following field sprays will be an important determinant of hand exposure and guide evaluation of gloves as direct dosimeters. DFR is routinely used to indirectly predict external harvester exposure at the PHI during risk characterization. For example, application of the transfer coefficient $\left(3,000 \mathrm{~cm}^{2} / \mathrm{h}\right.$; Dong 1999) to the DFR $\left(0.132 \mu \mathrm{g} / \mathrm{cm}^{2}\right)$ and an estimated $8 \mathrm{~h}$ work period yielded a potential external exposure of 3,168 $\mu \mathrm{g} /$ person (Table 3). Only 3 days later when the DFR was $0.012 \mu \mathrm{g} / \mathrm{cm}^{2}$, the estimated exposure was $288 \mu \mathrm{g} /$ person. Extreme or worst-case exposures predicted by DFR at the PHI likely do not properly represent harvester exposure potential at later times. This observation is especially pertinent to crops such as strawberries in sprayed fields that may be continually harvested by the same crews on a 3-5 day schedule during the growing season. Although glove residues may over-estimate hand exposure, they indicate a more gradual decline in pesticide availability than DFR as foliage residues age. The possibility that a glove dosimeter can be used to directly predict foliage residue availability and ultimately harvester exposure must be evaluated and validated using biomonitoring under field conditions.

The relationship between pesticide residues accumulated on gloves, potential dermal exposure, and absorbed dose must be clarified to determine whether gloves may be used as direct exposure dosimeters. Future harvester exposure estimates using gloves as direct dosimeters may represent a useful means to establish safe margins-ofexposure for multiple products used in pest management in strawberry farming.

Acknowledgments The California Strawberry Commission and Daren Gee of DB Specialty Farms, Santa Maria, CA supported and contributed to the development of this research project of the University of California Citrus Experiment Station, Riverside, CA. Gosia Meyer, Julie Penola and staff of primuslabs.com, Santa Maria are also gratefully acknowledged. 


\section{References}

Bradman A, Salvatore AL, Boeniger M, Castorina B, Snyder J, Barr DB, Jewell NP, Kavanagh-Baird G, Striley C, Eskenazi B (2008) Community-based intervention to reduce pesticide exposure to farmworkers and potential take-home exposure to their families. J Expo Sci Environ Epidemiol 19:79-89

Dong M (1999) Transfer factor for strawberry harvesters HSM99008. California Department of Pesticide Regulation, Sacramento, CA

Durham WF, Wolfe HR (1962) Measurement of the exposure of workers to pesticides. Bull World Health Org 26:75-91

Iwata Y, Knaak JB, Spear RC, Foster RJ (1977) Worker reentry into pesticide-treated crops. I. Procedure for the determination of dislodgeable pesticide residues on foliage. Bull Environ Contam Toxicol 18:649-655

Jensen IM, Whatling P (2010) Malathon: a review of toxicology. In: Krieger RI (ed) Hayes' handbook of pesticide toxicology, 3rd edn. Academic Press, San Diego, CA, p 1527

Krieger RI (1995) Pesticide exposure assessment. Toxicol Lett 82(83):65-72

Krieger RI, Dinoff TM (2000) Captan fungicide exposures of strawberry harvesters using THPI as a urinary biomarker. Arch Environ Contam Toxicol 38:398-403

Krieger RI, Driver JH, Ross JH (2006) Toxicology and metabolism relating to human occupational and residential chemical exposures. In: Proceedings IUPAC 11th international congress of pesticide chemistry, Kobe, Japan, August 6-11, 2006

Krieger RI, Blewett TC, Edmiston S, Fong H, Gibbons D, Meinders D, O'Connell L, Ross JH, Schneider F, Spencer J, Thongsinthusak T (1991) Gauging pesticide exposure of handlers (Mixer/
Loader/Applicator) and harvesters in California agriculture. Med Lav 81:474-479

Li Y (2009) Occurrence and the exposure potential of selected pesticide residues in strawberries, particularly preformed human malathion biomarkers in leaves and berries. Dissertation, University of California, Riverside

Luke MA, Froberg JE, Doose GM, Masumoto HT (1981) Improved multiresidue gas chromatographic determination of organophosphorus, organonitrogen, and organohalogen pesticides in produce, using flame photometric and electrolytic conductivity detectors. J Assoc Off Anal Chem 64:1187-1195

Ross JH, Dong MH, Krieger RI (2000) Conservatism in pesticide exposure assessment. Reg Toxicol Pharmacol 31:53-58

Van Hemmen JJ, van der Jagt KE, Brouwer DH (2006) Assessment of postapplication exposure to pesticides in agriculture. In: Martinez JL, Garrido Frenich V, Garrido Frenich A (eds) Pesticide protocols. Human Press, Totowa, NJ, p 149

Whitmyre GK, Ross JH, Lunchick C, Volger B, Singer S (2003) Biphasic dissipation kinetics for dislodgeable foliar residues in estimating postapplication occupational exposures to endosulfan. Arch Environ Contam Toxicol 46:17-23

Williams RL, Reifenrath WG, Krieger RI (2005) Artificial sweat enhances dermal transfer of chlorpyrifos from treated nylon carpet fibers. J Environ Sci Health B 40:535-543

Zhang XF (2005) Human pesticide exposure analysis: urine biomarkers of organophosphorus insecticides, malathion, 2, 4-D, and triclopyr. Dissertation, University of California, Riverside

Zweig G, Leffingwell JT, Popendorf W (1985) The relationship between dermal pesticide exposure by fruit and dislodgeable foliar residues. J Environ Sci Health B 20:27-59 